\title{
Numerical Simulation of Thermal Theory of Sintered Coal Gangue Self-Insulation Block and Wall
}

\author{
Zhai Hongxia ${ }^{1}$, Pang Kang ${ }^{2}$, Cheng Baoquan ${ }^{2, a}$ and Li Xuanyi ${ }^{2}$ \\ ${ }^{1}$ School of Materials Science and Chemical Engineering, ANHUI JIANZHU UNIVERSITY, 234601 Hefei, Anhui Province, China \\ ${ }^{2}$ School of Civil Engineering, ANHUI JIANZHU UNIVERSITY, 234601 Hefei, Anhui Province, China
}

\begin{abstract}
As a new building material, sintered coal gangue self-insulation block can not only make efficient use of industrial waste but also have a stronger heat preservation effect. In this paper, we use sintered coal gangue self-insulation block with staggered rectangle holes and wall as objects which can be seen commonly in the Anhui market. Through studying block type, wall thickness and masonry mortar type's effects on the heat preservation of the wall based on ANSYS numerical modeling, it proves that with special masonry mortar, sintered coal gangue self-insulation block can reach the best energy-saving effect, which meets the need of green building and sustainable building .
\end{abstract}

\section{Introduction}

With the increase of national requirements in energy saving and emission reduction, the development of building insulation material and the study in thermal performance are attached great importance. Gangue is one of the salvaged materials in coal mining in our country, which is regarded as cost-effective material not only for it can be used as both raw material and fuel in producing building materials but also for it can keep active after burning. By using the gangue as raw material to produce sintered self-insulation hollow block can improve the whole capability of block.

Li Ping gained the conclusion that the sintered coal gangue masonry wall meet the national energy conservation requirement of saving $65 \%$ resource from the thermal performance testing in sintered coal gangue self-insulation block [1]. Li Donghong points out that saving building energy consumption can be started from the study of exterior wall structure-sintered insulation hollow block. Reducing the thermal conductivity of sintered insulated hollow block, thus improving the thermal insulation ability of wall[2]. Ammar Bouchair established a theoretical model for simulating the thermal performance of the hollow brick, and he carried out the steady-state thermal analysis of the sintered hollow brick wall; The study shows that increase the hole length of the sintered hollow brick, add adiabatic insulation material in the slot, and reduce the radiation rate on the surface of the hole can improve the thermal performance of brick. [3].

In this paper, we discuss the most energy-saving thermal insulation material collocation method through the numerical simulation and comparison of the insulation effect of sintered coal gangue self-insulation block and ordinary clay block as well as walls with different masonry mortar or different thickness.

\section{Block Selection and Determination of Parameters}

\subsection{Selection of Block}

Normally, the holes of hollow block are different. Li Jiancheng from South China University of Technology Subtropical Building Research Office, proved that in the same hole rate, under the condition that the outer wall and inner wall thickness of the hollow block are the same, the rectangular hole heat transfer coefficient is the smallest, the diamond is second, the circle is the largest whether considers the radiation of the inner surface of the hollow block or not[5] By calculating the average thermal resistance of block with different holes, Western studies have found that the best arrangement of sintered block holes is staggered, so this paper studied the coal sintered gangue selfinsulation block with staggered and rectangular holes, which is commonly used in the Anhui market. The block sizes are $240 \mathrm{~mm} \times 200 \mathrm{~mm} \times 190 \mathrm{~mm}$ and $240 \mathrm{~mm} \times 240 \mathrm{~mm} \times 19 \mathrm{~mm}$.

\footnotetext{
${ }^{\mathrm{a}}$ Corresponding author: 1214066346@qq.com
} 


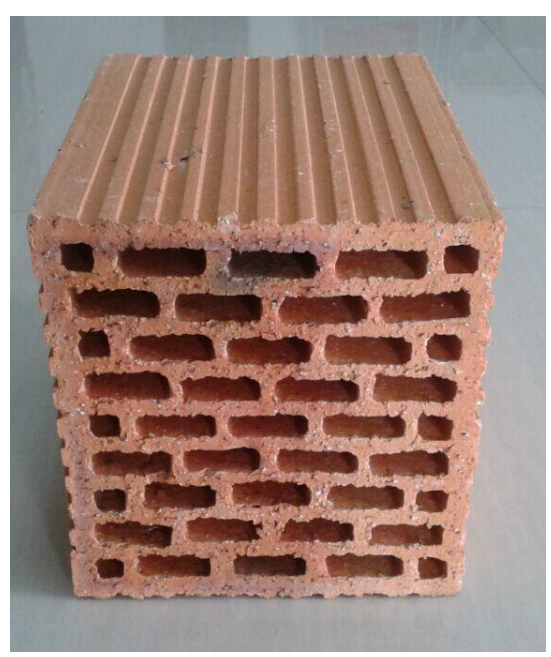

Figure.1. Picture of Real Sintered Coal Gangue Self-insulation Block

\subsection{Determination of material parameters}

By referring to the code of design for civil building thermal engineering gb50716-1993, the thermal conductivity of the selected block and mortar can be obtained which are Shown in Table.1.

Table.1. Thermal conductivity of related materials.

\begin{tabular}{|c|c|}
\hline Name of the Material & $\begin{array}{c}\text { Heat Conductivity } \\
\text { Coefficient }\end{array}$ \\
\hline Clay Brick & 0.76 \\
\hline Colliery Wastes Brick & 0.57 \\
\hline Air & 0.087 \\
\hline Common Cement Mortar & 0.93 \\
\hline Special Cement Mortar & 0.30 \\
\hline
\end{tabular}

\subsection{Determination of environmental parameters}

Referred to "indoor air quality standard" GB t18832002 and the main meteorological parameters of Anhui Province, we assume that the summer outdoor temperature is $28.1{ }^{\circ} \mathrm{C}$ and indoor is $25{ }^{\circ} \mathrm{C}$, winter outdoor temperature is $2.6{ }^{\circ} \mathrm{C}$ and indoor is $20{ }^{\circ} \mathrm{C}$. Above all, the outdoor and indoor limited simulation values are $2.6{ }^{\circ} \mathrm{C}$ and $20^{\circ} \mathrm{C}$ respectively.(The outdoor and indoor surface convection heat transfer coefficients are $25 \mathrm{w} / \mathrm{m} 2 * \mathrm{k}$. and $9.1 \mathrm{w} / \mathrm{m} 2 * \mathrm{k}$ respectively.)

\section{Modeling and Computing}

\subsection{Model Building}

This paper selects sintered coat gangue self-insulation block and ordinary clay brick block with the same hole rate $(39.6 \%)$ and the same size $\left(240 \mathrm{~mm}^{*} 200 \mathrm{~mm}^{*} 190 \mathrm{~mm}\right)$, using the ANSYS software to simulated the thermal performance of two blocks. Steps are as follow.

Define the job file name

Define the material attribute value

Define the section size type

Set up the geometric model (point, line, surface)

Mapped Meshing

Impose constraints and loads

Solve and get the result

\subsection{The Numerical Modeling of Block}

The result of value simulation is shown in the figure:

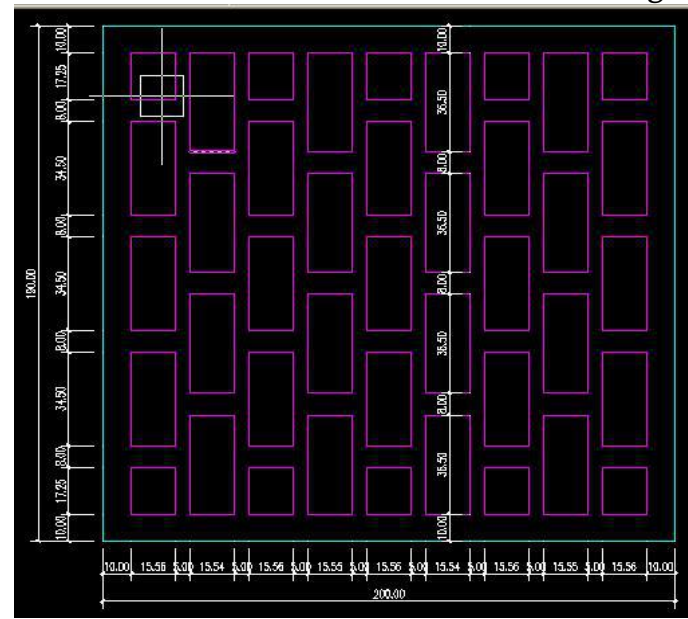

Figure.2. Set up brick model

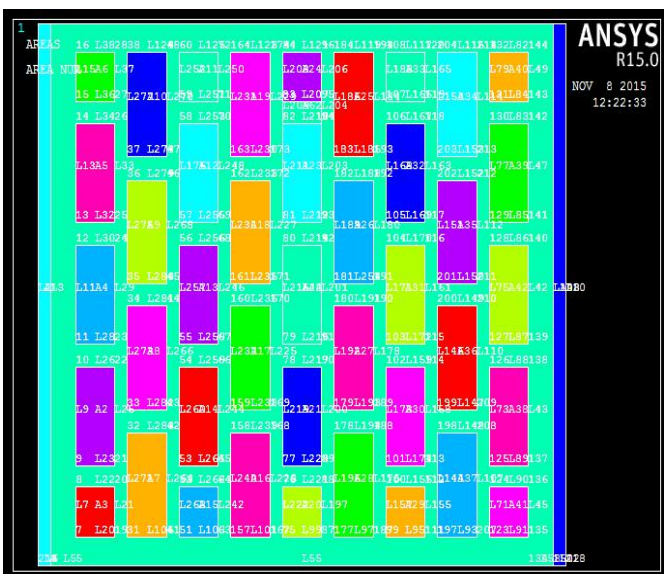

Figure.3. Meshing 


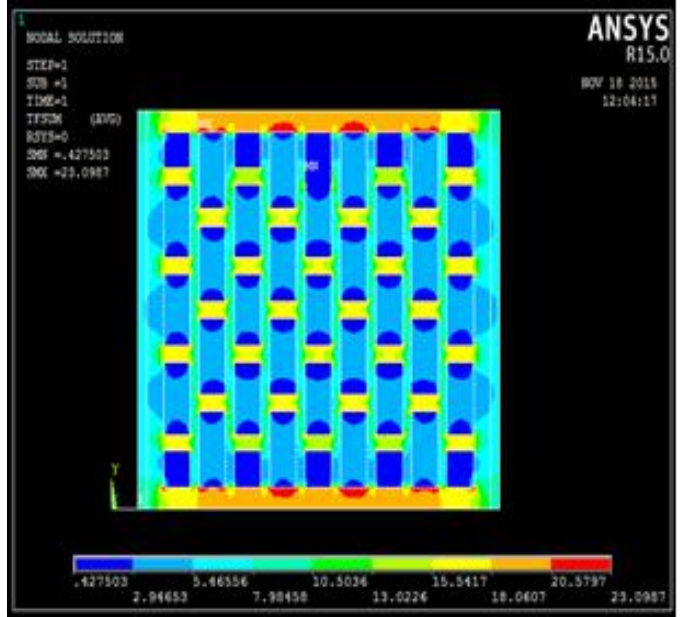

Figure.4. Heat Flux distribution diagram of sintered coal gangue self-insulation block

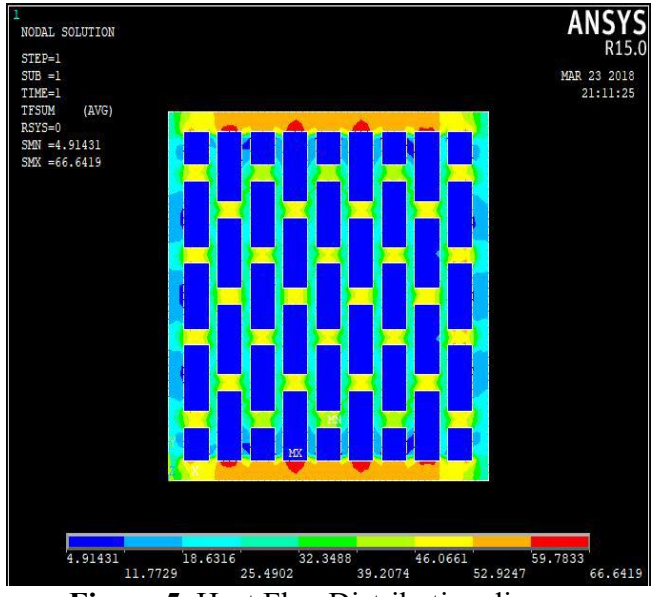

Figure.5. Heat Flux Distribution diagram of ordinary clay block

\subsection{Discussion}

This paper uses the heat transfer coefficient as the index to evaluate the thermal performance of the block. The calculation formula is $\mathrm{q}=\mathrm{K}(\mathrm{T} 1-\mathrm{T} 2)$, where $\mathrm{K}$ is heat transfer, $\mathrm{q}$ is average heat flow; $\mathrm{T} 1$ and $\mathrm{T} 2$ are the average temperature on each side of the block value.

Under the same condition, the maximum heat flow of sintered coal gangue self-insulation block is $\mathrm{q}=\frac{23.48 \mathrm{w}}{\mathrm{m} 2 \times \mathrm{C}}$, calculation result is $\mathrm{K}=1.327<1.5$ which meets the design standards for energy efficiency of residential buildings in Anhui province. While the maximum heat flow 1,5 of ordinary clay blocks is $\mathrm{q}=\frac{66.64 \mathrm{w}}{\mathrm{m} 2 \times \mathrm{c}}, \mathrm{K}=3.76>1.5$, obviously beyond the standard that regulated in the design standards for energy efficiency of residential buildings in Anhui province

Under the same conditions, the thermal insulation resistance of sintered coal gangue self-insulation block is better than the ordinary clay blocks, which meets the requirement of energy conservation and environmental protection better.

\section{Numerical simulation of thermal performance of masonry walls}

In the third part we draw a conclusion that sintered coal gangue self-insulation block has good thermal insulation effect by analysing single block rectangular block.

Next, this paper discusses the effect of mortar's type on the thermal performance of masonry wall under steady temperature through simulation and comparison of thermal performance of sintered coal gangue self-insulation block walls with two different kinds of masonry mortar (ordinary cement mortar(The heat conductivity coefficient is $0.93 \mathrm{w} / \mathrm{m} \times \mathrm{k}$ ) and special cement mortar(The heat conductivity coefficient is $0.30 \mathrm{w} / \mathrm{m} \times \mathrm{k}$ ) ) and different thickness (200mm and $240 \mathrm{~mm}$ ).

\subsection{Modeling Calculation}

The process of wall modeling is similar to that of the third part. Its grid partitioning method is shown in the figure.

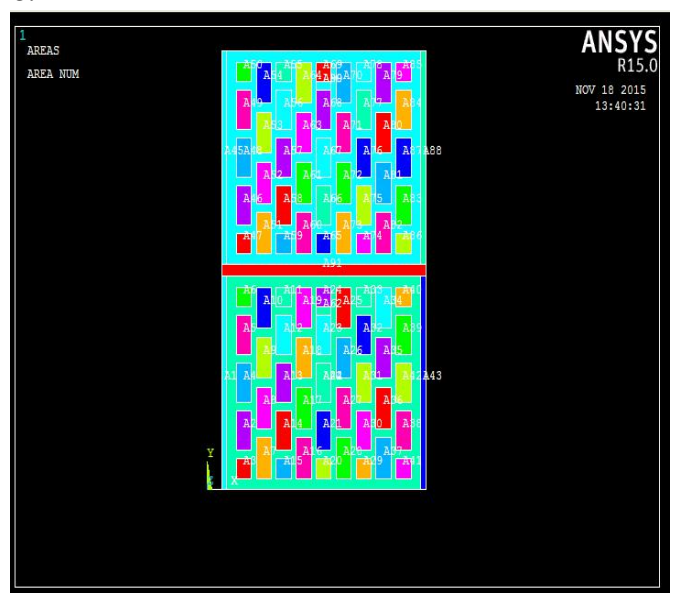

Figure.6. Picture of wall modeling grid partitioning method

\subsection{The result of value simulation}

Under steady temperature, the numerical simulation results of the thermal performance of two kinds of sintering coal gangue with two kinds of masonry mortar (ordinary cement mortar and special cement mortar) and different thickness (200 $\mathrm{mm}$ and $240 \mathrm{~mm}$ ) are shown respectively in the figures. 


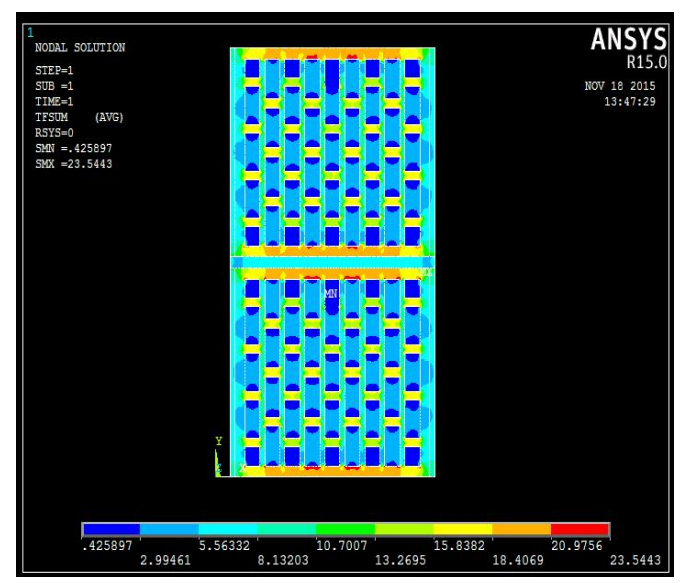

Figure.7. Heat flux distribution diagram distribution diagram of ordinary cement mortar block

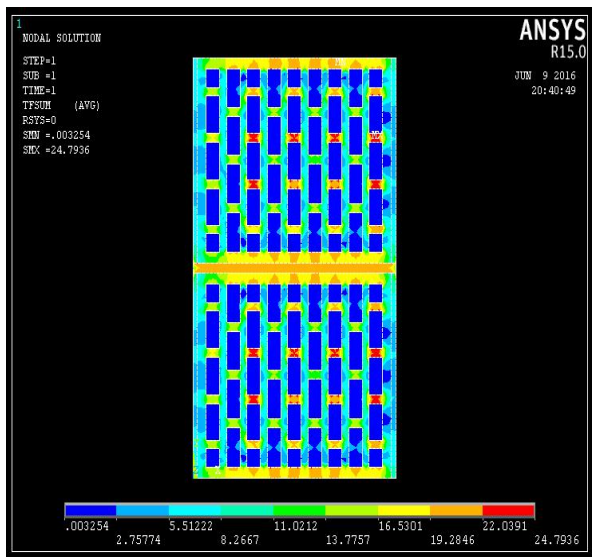

Figure.8. Heat flux distribution diagram distribution diagram of special cement mortar block

\subsection{Results Analysis}

By simulating values, we come to the conclusion that sintered coal gangue self-insulation block (thickness are both $200 \mathrm{~mm}$ ) with two different kinds of masonry mortar can meet the requirement of saving 50\% energy. The heat transfer coefficient of wall with special masonry mortar is smaller than that with cement mortar, which states special masonry mortar can do better in wall energy saving. With $240 \mathrm{~mm}$ thick masonry panel, using cement mortar can only save $50 \%$ energy, while using special masonry mortar can save $65 \%$ energy.

\section{Conclusion}

Compared to traditional clay brick blocks, sintered coal gangue self-insulation block can not only use industrial waste more efficiently, but also have better heat preservation and smaller heat transfer coefficient, which more accord with the requirements of green building and sustainable building. With special masonry mortar, the sintered coal gangue selfinsulation block can gain better thermal performance.
This paper's conclusion provides support for the promotion of this environmental-friendly building material.

\section{Reference:}

1. Li Ping, thermal test and simulation of selfinsulation block. China Concrete and Cement Products 2015 (08);

2. Li Donghong. The preparation technology and groove optimization design of energy-saving sintered thermal insulation hollow block[D]. Xi'an University of Architecture and Technology. 2017;

3. Ammar, BOUCHAIR. Steady state theoretical model of fired clay hollow bricks for enhanced external wall thermal insulation[J].Building and Environmen,2008,43 (10);1603-1618;

4. Feng Kai, Development trend and suggestion of green energy-saving sintered brick block, BRICKTILE 2017 (04);

5. Guo Yongliang, The superiority of coal gangue hollow brick from the Angle of building energy saving. Jilin Building Materials 2002 (03);

6. Li Jiancheng, The effect of pore type of concrete hollow block on its fine thermal properties. [J]. China Concrete and Cement Products1995.05;

7. Xu Shujie, Study on the design of full coal gangue sintered modulus of porous brick and the thermal performance of the masonry. BRICK-TILE 2006 (05);

8. Li G, Jones N. Development of rubberized syntactic foam [J]. Composites Part A Applied Science \& Manufacturing, 2007, 38(6):1483-1492. 